Istanbul Finance Congress, November 1-2, 2018, Istanbul, Turkey.

\title{
SECTORAL PERSISTENCE OF TURKISH INFLATION RATES
}

\author{
DOI: 10.17261/Pressacademia.2018.975
}

PAP-IFC- V.8-2018(7)-p.29-33

\section{Bekir Asik}

Beykent University, Department of Economics, Istanbul, Turkey.

bekirasik@beykent.edu.tr, ORCID: 0000-0002-2221-016

To cite this document

Asik, B. (2018). Sectorel persistence of Turkish inflation rates. PressAcademia Procedia (PAP), V.8, p.29-33.

Permemant link to this document: http://doi.org/10.17261/Pressacademia.2018.975

Copyright: Published by PressAcademia and limited licenced re-use rights only.

\section{ABSTRACT}

Purpose- Persistence of inflation refers to the speed of convergence of inflation to the long term mean after a shock. As the speed of convergence to the long run value is not high, monetary policy makers have to respond aggressively to decrease the effects of that shock. Therefore, the degree of inflation persistence should be determined correctly to take the right policy application.

Methodology- Persistence of inflation in CPI and PPI series is investigated by using the sum of the autoregressive coefficients of a univariate model with breaks in the mean of inflation in this study.

Findings- When we investigated persistence of CPI and PPI series and subgroups with breaks in inflation, we find inflation persistence is much lower in all groups.

Conclusion- However, the persistence of inflation has decreased after adopting the inflation targeting policy, this decrease in persistence has not reduced the persistence in the whole period to low levels.

Keywords: Inflation, structural breaks, autoregression

JEL Codes: E31, C22

\section{TÜRKIYE'DE ENFLASYON ORANLARININ SEKTÖREL DIRENCI}

\section{ÖZET}

Amaç- Enflasyon direnci, enflasyon serisine gelen bir şokun sonucunda serinin uzun dönemli ortalamasına yakınsama hızını ifade eder. Bu yakınsama hızı yüksek değilse, şokun etkisini azaltmak için para politikası uygulayıcıları daha sert tedbirler uygulamak durumundadır. Dolayısıyla, enflasyon direncinin doğru tespit edilmesi doğru politikaların uygulanabilmesi için gereklidir. Bu amaçla, Türkiye enflasyon oranlarının direnç değerleri tespit edilmiştir.

Yöntem- Literatürde enflasyon direncini hesaplamak için farklı yöntemler kullanılmaktadır. Bu çalışmada, TÜFE ve ÜFE serilerindeki direnç seviyesini belirleyebilmek için yapısal kırılmanın dahil edildiği tek değişkenli ardaşık bağlanım modelindeki katsayıların toplanması yöntemi kullanılmıştır.

Bulgular- TÜFE ve ÜFE serileri ve bu serilerin alt gruplarında direnç değerini hesaplamak için yapısal kırılmalı yöntem kullanıldığında, yapısal kırılmanın dahil edilmeden yapılan tahminlere göre enflasyon serilerindeki direnç değeri düşmektedir. Ayrıca enflasyon hedeflemesi politikası benimsendikten sonra enflasyon serilerindeki direnç değerleri düşmektedir.

Sonuç- Genel olarak bulunan sonuç enflasyon serilerinde direncin kırılma tarihinden sonra azaldığı yönündedir. Ancak dirençteki bu azalma, incelenen bütün dönemdeki enflasyon direncini çok düşük değerlere çekememiştir.

Anahtar Kelimler: Enflasyon, yapısal kırılma, ardışık bağlanım

JEL Kodları: E31, C22

\section{GíRiş}

Para Politikasının oluşturulmasında önemli bir unsur olan enflasyon direnci, enflasyona gelen bir şok sonrası enflasyonun uzun dönem ortalamasına yakınsama hızını ifade eder. Enflasyona gelen bir şok sonrasında enflasyonun uzun dönem ortalamasına yakınsama hızı azaldığı zaman enflasyonda direnç olduğu söylenir. Kısa zaman içerisinde şokun etkisi yok olursa, enflasyonda direncin olmadığı veya zayıf olduğu anlamına gelir.

Enflasyonun uzun dönemli ortalamasına yakınsama hızı azaldıkça para politikası kuralı değişecek ve daha katı politika tedbirleri uygulanacaktır. Mishkin (2007), direnç değerinin düşük olması durumunda politika yapıcılarının enflasyona daha az şiddetle müdahale edeceğini ifade etmiştir. Bu nedenle enflasyon direncinin bilinmesi etkin politikaların uygulanabilmesi için gereklidir. 
Literatürde ilk olarak enflasyondaki direncin yüksek ve bire yakın olduğu şeklinde sonuçlar bulunmuştur (Gadzinski ve Orlandi (2004), O. Reilly ve Whelan (2005)). Ancak daha sonraki çalışmalarda enflasyonda gözlemlenen kırılmaların, enflasyon sürekliliği tahminlerine dahil edildiğinde enflasyon direncinin birin altında olduğu tespit edilmiştir. Levin ve Pilger (2004) çalışmasında enflasyonda kırılma analize dahil edilmediği zaman ABD’nin 48 enflasyon serisinden 8'inde birim kök reddedilirken, kırılmanın analize dahil edildiği durumda 29 seride birim kök reddedilmiştir. Cecchetti ve Debelle (2006), 16 ülke için yaptıkları çalışmada kırılmanın modellenmediği zaman direnç değerlerini ortalama 0.80; kırılmaların modellendiği zaman direnç değerlerinin ortalama 0.29 olduğu sonucuna ulaşmışlardır.

Petrassi ve Oliveria (2009) 23 sanayileşmiş ve Türkiye'nin dahil olduğu 17 gelişmekte olan ülkenin TüFE verilerini kullanarak elde ettikleri sonuçlara göre sanayileşmiş ülkelerde enflasyon direncinin daha düşük olduğu sonucuna varmışlardır. Literatürde, ortalama enflasyondaki kırılmaları analize dahil eden çalışmalarda, kırılmaların para politikası rejim değişikliklerine denk geldiği ifade edilmiştir. Capistran ve RamosFrancia (2007), Latin Amerika için yaptıkları çalışmada kırılmayı modele dahil etmediklerinde ortalama direnç değerini 0.77 olarak tespit etmişlerdir. Bir kırılma tespit edilen çalışmalarda bu değer 0.29; 2 kırılma tespit edilen çalışmalarda 0.39; 3 kırılma tespit edilen ülkelerde 0.62 ve 4 kırılma tespit edilen çalışmalarda ise 0.35 değerini bulmuşlardır. D’Amato ve diğerleri (2007) ise Arjantin için yaptıkları çalışmada kırılmanın dahil edilmediği çalışmada direnç değerini 0.80 , kırılmayı dahil edince direnç değerini 0.56 olarak tespit etmişlerdir.

Literatürde alt sektörlerdeki enflasyon direncinin genel enflasyon seviyesindeki dirence göre daha düşük olduğuna dair bir görüş bulunmaktadır. Babecky ve diğerleri (2009) çalışmasına göre enflasyon direncindeki yüksek değerler elde edilmesinin en önemli nedeni olarak toplulaştırma hatasını işaret etmektedirler. Alt sektörlerdeki endekslerin toplulaştırılarak genel enflasyona dönüştürülmesiyle genel enflasyondaki direnç değerinin daha yüksek olduğu tespit edilmiştir. Altissimo ve diğerleri (2006) çalışmalarında sektörel fiyat endekslerini de kullanmışlardır. Bu çalışmaya göre işlenmemiş gıda ve enerji sektörleri düşük direnç değerlerine sahipken, hizmet ve sanayi mallarında direnç değerleri daha yüksek çıkmıştır. Bilke (2005) çalışmasında kırılmanın analize dahil edilmesiyle enflasyonun direnç değerlerinde ciddi farklılıklar olduğunu ve hizmet ve sanayi mallarında direncin daha yüksek, gıda-enerji sektörlerinde direncin daha düşük olduğu sonucuna varmışlardır. Lünnemann ve Matha (2004) ise 15 AB ülkesi için yaptıkları çalışmada sektörler arasında ve ülkeler arasında ciddi farklılıklar tespit etmişlerdir. Bu çalışmada hizmet ve dayanıklı mallarda direnç değerleri daha düşük bulunmuştur.

Literatürde enflasyondaki direncin zaman içerisinde azalıp azalmadığına dair bir fikir birliği bulunmamaktadır. Clark (2006) ABD için yaptığı çalışmasında enflasyondaki direncin zaman içerisinde azaldığı sonucuna varmıştır. Benati (2008), 10 gelişmiş ülke için yaptığı çalışmada, iki ülke haricinde, direnç değerinde azalma tespit etmiştir. O’Reillay ve Whelan (2005) ise yaptıkları çalışmada direnç değerinin 0.95 olduğunu ve önemli bir değişim göstermediğini ifade etmişlerdir. Pivetta ve Reis (2008) ise lineer olmayan Bayes yöntemiyle yaptıkları çalışmada ABD enflasyon verilerinde yüksek bir direnç bulmuşlar ve bu değerlerin değişmediğini ifade etmişlerdir.

Enflasyonun direnç değerleri Türkiye için de araştırılmıştır. Bu çalışmalardan Balcılar (2004), ARFıMA modelini kullanarak Türkiye'deki enflasyon verilerindeki direnç değerini araştırmış ve direnç değerini 0.40 bulmuştur. Kutlar ve Turgut (2006) çalışmasında ise bu değer 0.45 civarında bulunmuştur. Şahin ve Çetinkaya (2009) çalışmasında, 1988.01-2007.12 zaman diliminde, TÜFE ve TEFE sektörel verilerini kullanarak otoregresif katsayılar toplamını En Küçük Kareler yöntemiyle tahmin etmişlerdir. Çalışmalarında kırılma tarihlerini Nisan 1994 ve Şubat 2001 olarak belirlemişler ve modellerine Şubat 2001 tarihindeki kırılmayı ekleyerek yaptıkları tahminlerde direnç değerlerinin düştüğü sonucuna ulaşmışlardır. Kırılmanın dahil edilerek yapılan tahminler sonucunda TÜFE'nin direnç değeri 0.77, TEFE'nin direnç değeri ise 0.66 olarak bulunmuştur. Özçiçek (2011) de TÜFE ve TEFE serilerinin direnç değerini 1994.01-2008.12 zaman aralığında otoregresif katsayılar toplamını En Küçük Kareler yöntemiyle tahmin etmiştir. Özçiçek (2011) serilerde kırılma tarihinin genelde 2002'nin ilk aylarında olduğunu tespit etmiştir. Kırılmayı modele dahil ettiği modellerin tahmin sonuçlarına göre direnç değerleri, kırılmanın dahil edilmediği modellerin sonuçlarına göre ciddi oranda düşmüştür. Yapısal kırılmanın olduğu tarih sonrasında direnç değerini de tahmin eden Özçiçek (2011), direnç değerinin yapısal kırılma tarihinden sonra düştüğüne dair bir kanıt bulamamıştır.

Bu çalışmada da Türkiye TÜFE ve ÜFE serilerinin direnç değeri araştırılmıştır. İncelenen zaman diliminde yapısal bir kırılmanın analize dahil edilmediği durumlarda sonuçların güvenilirliğini azalttığı için çalışmamızda öncellikle yapısal kırılmaların tarihi tespit edilmiş ve yapısal kırılmanın da dahil edildiği model tahminiyle direnç değerleri bulunmuştur. Ayrıca çalışma kapsamında enflasyon direncinin, enflasyon hedeflemesine geçildikten sonra azalıp azalmadığı araştırılmıştır.

\section{KULLANILAN VERI VE YÖNTEM}

Çalışmada TÜFE için iki veri seti kullanılmıştır. Veri setlerinden birisi 1995. M1 - 2004. M12; ikincisi ise 2003. M1-2018.M6 zaman aralığındadır. İki farklı veri seti kullanıımasının nedeni, çalışma kapsamında enflasyon verilerinin direncini araştırırken sektörel bazda bir inceleme yapılmasıdır. TÜiK, 2003 yılını baz alarak, yeni bir enflasyon sepeti oluşturmuş ve TÜFE'nin alt başlıklarının tanımını değiştirmiştir. Bu nedenle 1994 bazlı ve 2003 bazlı iki farklı veri kümesi bulunmaktadır. Sektörel tanımların değiştirilmesi nedeniyle iki farklı veri seti bulunmakta ve bu veri setleri birleştirilememektedir. Bu nedenle çalışma kapsamında iki farklı zaman aralığında TüFE'nin sektörel direnci incelenmiştir. Sadece genel TÜFE verilerinin direnci 1995.M1-2018.M6 zaman diliminde incelenmiştir.

Çalışma kapsamında ÜFE genel endeksi ve alt kollarının da enflasyon direnci araştırılmıştır. ÜFE alt kollarının tanımında bir değişiklik yapılmadığı için 1995. M1 - 2018. M6 zaman aralığında hem genel endeks hem de alt kollarının direnç değerleri hesaplanmıştır.

Verilerin direncini araştırmadan önce endeks, CENSUS X-12 yöntemiyle, mevsimsellikten arındırılmış ve verilerin logaritması alınmıştır. Verilerin logaritması alındıktan sonra farkları alınarak enflasyon değerleri elde edilmiştir. Genel endekslerin ve alt kollarının direnç değerleri hesaplanmadan önce serilere kırılma testi uygulanmıştır.

Bu çalışmada iki kırılma analizi kullanılmıştır. Kırılma analizlerinden ilki Bai ve Perron (2003)'tür. Genel model şu şekildedir:

$$
y_{t}=x_{t}^{\prime} \beta+z_{t}^{\prime} \delta_{j}+u_{t} \quad \mathrm{j}=1,2,3, \ldots ., \mathrm{m}+1 ; \mathrm{t}=1,2,3, \ldots, \mathrm{T} .
$$


Bu regresyonda $x$ ve $z$ açıklayıcı değişkenlerdir. Sistemde $m$ tane kırılma olduğu için $m+1$ tane de rejim olduğu varsayılmaktadır. Kırılma tarihleri $T_{1}, T_{2}, \ldots, T_{m}$ bilinmemektedir ve tahmin edilecektir. Kırılma tarihleri bilinemediği için toplam hata kareleri toplamının minimize eden değerler bulunacaktır.

$$
S_{T}=\left(T_{1}, T_{2}, \ldots, T_{m}\right)=\sum_{i=1}^{m+1} \sum_{t=T_{i-1}+1}^{T_{i}} y_{t}-x_{t}^{\prime} \beta-z_{t}^{\prime} \delta_{j}^{2}
$$

Tahmin edilen kırılma tarihleri $\left(\widehat{T}_{1}, \ldots ., \widehat{T}_{m}\right)=\operatorname{argmin}_{T_{1}, T_{2}, \ldots, T_{m}} S_{T}\left(T_{1}, T_{2}, \ldots, T_{m}\right)$ şeklinde gösterilir. Bai ve Perron (2003) bu eşitliği sağlayan değerleri bulmak için $T(T+1) / 2$ adet hata karelerini toplamını hesaplayan bir algoritma kullanmaktadırlar. Bu değerlere ek olarak, makalede güven aralığı hesaplaması ve iki test istatistiği de tarif edilmiştir. Bunlardan ilki $\mathrm{m}=0$ hipotezine karşılık $\mathrm{m}=\mathrm{k}$ hipotezini sınayan supF tipi istatistik; ikincisi ise $\mathrm{m}=I^{\prime}$ ye karşı $\mathrm{m}=1+1$ sınayan $\sup F_{t}(I+1 / I)$ test istatistiğidir.

Kırılma analizlerinden ikincisi ise Quandt-Andrews kırılma testidir. Quandt-Andrews kırılma testi, bir veri setinde belirlenen bir regrsesyondaki bir veya birden fazla bilinmeyen yapısal kırılmayı tespit eder. Quandt-Andrews kırılma testi, iki tarih aralığında ( $\tau_{1}$ ve $\tau_{2}$ ) Chow kırılma testini uygular. Chow testinden elde edilen $\mathrm{k}$ tane test istatistiği tek bir istatistiğe indirgenir ve " $\tau_{1}$ ve $\tau_{2}$ tarihleri arasında yapısal kırılma yoktur" sıfır hipotezi sınanır.

Enflasyon verilerinin kırılma analizi yapıldıktan sonra verilerin sürekliliği incelenmiştir. Bu sürekliliği incelemek için literatürde bir çok yöntem uygulanmaktadır. Dias ve Marques (2005) bu yöntemleri karşılaştırmıştır. Bu çalışmada kullanılan yöntem ardışık bağlanım katsayılarının toplamıdır. Enflasyon $(\pi)$ tek değişkenli bir zaman serisi şeklinde modellenirse,

$$
\pi_{t}=\mu+\sum_{j=1}^{K} \alpha_{j} \cdot \pi_{t-j}+\varepsilon_{t}
$$

Direnç ölçüsü bu denklemdeki eğim katsayılarının toplamı şeklinde bulunur. $\rho=\sum_{j=1}^{K} \alpha_{j}$ genişletilmiş Dickey-Fuller formunda yazıldığında

$$
\Delta \pi_{t}=\mu+\rho . \pi_{t-1}+\sum_{j=1}^{K-1} \gamma_{j} \cdot \Delta \pi_{t-j}+\varepsilon_{t}
$$

hesaplanması daha kolay bir hal alır. Son olarak modele $n$ tane yapısal kırılma eklendiğinde model şu hali alır:

$$
\Delta \pi_{t}=\mu_{0}+\sum_{b=1}^{n} \mu_{b} \cdot D_{b}+\rho \cdot \pi_{t-1}+\sum_{j=1}^{K-1} \gamma_{j} . \Delta \pi_{t-j}+\varepsilon_{t}
$$

$D_{b}$ kırılma tarihine kadar sıfır ondan sonra da bir değerini alan kırılma kuklası, $\mu_{b}$ ise ortalamadaki değişmeyi temsil eden katsayıdır.

\section{GENEL VE ALT GRUPLARDA ENFLASYON SERISINDE KIRILMA VE DIRENÇ DEĞERLERi}

Enflasyon serilerinde gözlemlenen bir yapısal kırılma yapılan analizlerin sonuçlarını etkilemektedir. Türkiye enflasyon serilerinin direnç değerlerini araştırmadan ve analiz etmeden önce bu serilere uygulanan kırılma testleri sonuçlarını incelemek gerekmektedir. TüFE genel serisi ve alt sektörleri genel olarak 2002 yılının ilk aylarında yapısal kırılmaya uğramaktadır. 1995-2004 zaman aralığında TÜFE'den elde edilen enflasyon serisi 2002'nin ikinci ayında; giyim ve ayakkabı serisi 2002 yılının on birinci ayında; konut 2001'in onuncu ayında; ev eşyası 2002'nin ikinci ayında; sağıık 2000 yııının üçüncü ayında; ulaştırma 2002 yılının ikinci ayında; eğlence ve kültür 2001 yılının onuncu ayında; eğitim 1999'un dokuzuncu ayında; lokanta, pastane ve otel 1994'ün dördüncü ayında ve çeşitli mal ve hizmetler ise 2001'in on ikinci ayında yapısal kırılmaya uğramıştır. Ancak giyim ve ayakkabı, konut, sağlık, eğlence ve kültür ve lokanta, pastane ve otel serileri ikinci bir yapısal kırılmaya uğramıştır. 2003.01-2018.06 zaman aralığında ise birçok seride yapısal kırılmaya rastlanmamıştır. Bu serilerden enerji ve gıda dışı mallar, temel mallar, dayanıklı mallar-altın hariç, kira ve diğer hizmetler serileri yapısal kırılmaya uğramıştır.

1995.01-2018.06 zaman aralığındaki ÜFE serileri de genelde 2002 yılının ilk aylarında yapısal kırılmaya uğramıştır. ÜFE genel endeksi 2002 yılının ikinci ayında; madencilik ve taş ocakçıı̆ı 2003 yılının dördüncü ayında ve imalat serisi 2002'nin birinci ayında yapısal kırılma gerçekleşmiştir.

Regresyon denklemleri (3) ve (4)'ü tahmin etmek için gecikme sayısının belirlenmesi gerekmektedir. Özçicek (2011), bütün tahminlerinde 6 gecikme kullanarak gecikme sayısındaki farklılığın sonuçlar üzerinde bir etkisinin olmamasını amaçladığını ifade etmiştir. Ancak literatürde genelde aylık verilerde 12 gecikme kullanılmaktadır. Cecchetti ve Debelle (2006) da bütün tahminlerinde 12 gecikme kullanmıştır. Çalışma kapsamında da bütün regresyon tahminlerinde 12 gecikme kullanılmıştır. Enflasyon serilerinde direnç değerlerini ölçmek için 12 gecikme kullanılarak regresyon (3) ve (4) tahmin edilmiştir. TÜFE serilerinin 1995-2004 zaman dilimi ve 2003-2018 zaman dilimi için tahminler ayrı ayrı yapılmıştır. ÜFE serilerinin tahmini ise 1995-2018 zaman dilimi için yapılmıştır. Enflasyonda yapısal bir kırılmanın olduğu durumda sonuçların nasıl değiştiğini analiz edebilmek için ilk olarak yapısal kırılma modele eklenmeden tahminler yapılmıştır.

1995-2004 zaman diliminde, TÜFE serilerindeki en yüksek direnç değerler Konut (0.97), Lokanta, Pastane ve Otel (0.96) ve genel TÜFE serisinde (0.94) gözlenmektedir. En düşük değer ise Çeşitli Mal ve Hizmetler (0.77)'ye aittir. Ancak alt dallardaki enflasyon serilerinde ana serilere göre daha yüksek direnç değerlerine rastlanmaktadır. Hastane ve Hastane Dışı Tıbbi Hizmetler (1.07) ve Kira (0.99) yüksek değerlere; Sigara ve Tütün (-0.35), İlaçlar ve Tıbbi Ürünler (0.49), Özel Ulaşım Araçlarının Tamir ve Bakımı (0.47) ve Haberleşme (0.46) düşük değerlere sahiptir.

Literatürde olduğu gibi analize yapısal kırılma eklendiği zaman direnç değerlerinde gözle görülür bir düşüş bulunmaktadır. Genel TÜFE ve ana sektörlerdeki bütün enflasyon serilerinde büyük oranlı azalmalar gözlenmiştir. Sağlık, ulaştırma ve eğitim sektörlerindeki düşüşün oldukça büyük olduğu göze çarpmaktadır. Direnç değerlerindeki bu büyük düşüş, enflasyon serilerinde kırılmanın ihmal edilmemesi gerektiğini işaret etmektedir. 
TÜFE serilerindeki direnç değerlerini analiz etmek için kullanılan ikinci veri seti 2003-2018 zaman aralığına aittir. Enerji ve Gıda Dışı Mallar, Temel Mallar, Dayanaklı Mallar (Altın Hariç), Hizmet, Kira, Lokanta ve Oteller, Ulaştırma Hizmetleri ve Diğer Hizmetler gibi sektörlerde yapısal kırılmaya rastlanmıştır.

2003-2018 zaman diliminde, TÜFE serilerindeki direnç değerlerine göre, bir önceki döneme göre, düşük değerlere rastlanmıştır. Kira (0.95), Hizmet (0.78), Diğer Temel Mallar (0.75), İşlenmiş Gıda (0.73) ve Temel Mallar (0.65) yüksek değerlere sahiptir. Kırılmanın olduğu sektörler için, kırılmanın eklendiği sonuçlara göre Kira (0.87) ve Diğer Hizmetler (0.41) haricinde büyük oranlarda düşüş vardır. Ancak kira ve diğer hizmetlerdeki gözlemlenen düşüş çok azdır.

1995.01-2018.06 zaman diliminde TÜFE genel serisinin, yapısal kırılma modele dahil edilmeden hesaplanan direnç değeri 0.95’tir. TÜFE serisinin, biri kök test sonuçlarına göre yapısal kırılma tarihi 2002 yılının ikinci ayıdır ve bu yapısal kırılma modele eklenerek yapılan model tahminine göre elde edilen direnç değeri 0.64'tür. Bu değer, 1994.01-2004.12 zaman dilimindeki genel enflasyon direncinden (0.70) çok farklı bir değer değildir.

Çalışmada ÜFE serilerinin direnç değerleri de araştırılmıştır. Kırılmanın analize dahil edilmeden yapılan tahmin sonuçlarına göre en yüksek değerler ÜFE genel endeks (0.90) ve Motorlu Kara Taşıtları, Römork ve Yarı Römork'a (0.91) aittir. En düşük değerler ise Ham Petrol ve Doğal Gaz (0.08), Kök ve Rafine Petrol Ürünleri (0.41) ve Metal Cevherleri (0.44)'e aittir. Yapısal kırılmanın dahil edildiği regresyon sonuçlarına göre ÜFE alt sektörlerde ciddi oranda düşüşler gözlenmiştir. Ancak bu düşüşlere rağmen ÜFE genel endeksinin değeri (0.59), Motorlu Kara Taşıtları Römork ve Yarı Römork (0.62), Gıda Ürünler (0.56) ve İmalat (0.47) yüksek değerlere sahiptir.

Literatürde, yapısal kırılmanın gerçekleştiği tarihten sonra direnç değerlerinin azaldığına dair genel bir kanı bulunmaktadır (Taylor, 1999, Cecchetti ve Debelle, 2006, Benati, 2008). Literatürdeki bu genel kanın aksine Özçiçek (2011) Türkiye enflasyon serilerinde bu durumun gözlenmediğini iddia etmektedir. Çalışmada da bu iddianın geçerliliğini tekrar test etmek için ÜFE serisi örneklemi 1995-2001 ve 2002-2018 alt dönemlerine ayrılmıştır. Alt dönemlerde elde edilen direnç değerleri genelde yapısal kırılmanın dahil edildiği uzun dönem sonuçlarına göre azalma göstermektedir. ÜFE genel endeks, imalat ve gıda ürünleri, her iki alt dönemde de, kırılmanın dahil edildiği sonuçlara göre daha düşük bir direnç değerine sahiptir. Bu analizden çıkan bir diğer sonuç 2002-2018 zaman aralığında ÜFE serilerinin direnç değerlerinde, bazı seriler haricinde, ciddi oranda düşüşler gözlenmektedir. Gıda ürünleri, ağaç ve mantar ürünleri, kağıt ve kağıt ürünleri, basım ve kayıt hizmetleri, temel eczacılık ürünleri ve diğer metalik olmayan mineral ürünler gibi endekslerde direnç değerleri yükselmiştir.

\section{SONUÇ}

Bu çalışmada enflasyon serilerinin direnç değerleri tek değişkenli bir modelde ardışık bağlanım katsayıları toplamı tahmin edilerek bulunmuştur. Bu modelin tahmin edilmesinde en önemli unsurlardan birisi incelenen serilerde yapısal kırılmanın olup olmadığıdır. TÜFE ve ÜFE serileri için yapısal kırılma testi iki farklı birim kök testiyle tespit edilmiştir ve iki test de ortak sonuçlar vermiştir ve test sonuçlarına göre 1995.01-2004.12 dönemi TÜFE ve 1995.01-2018.06 dönemi ÜFE serilerinde en az bir yapısal kırılma mevcuttur. 2003.01-2018.06 zaman aralığındaki TÜFE serilerinin büyük bir kısmında yapısal kırılma tespit edilememiştir. 1995.01-2004.12 dönemi TÜFE ve 1995.01-2018.06 dönemi ÜFE serilerinde kırılma tarihleri farklılık gösterse de çoğunlukla kırılma tarihi 2001'in son ayları ve 2002'nin ilk aylarında gerçekleşmektedir.

İncelenen serilerde kırılmanın dahil edilmediği tahmin sonuçlarına göre Türkiye'deki enflasyon direnci yüksek çıkmaktadır. Literatürde işaret edildiği gibi yapısal kırılmalar analize dahil edildiğinde enflasyon direnç değerleri düşmektedir. Literatürde bir başka kanı da enflasyonda gözlemlenen direnç değerinin sonraki dönemlerde azaldığıdır. Mishkin (2007), direnç değerlerinin sonraki dönemlerde azalmasını merkez bankalarının güvenirliliğinin artmasına ve beklentilerin enflasyon artışına izin vermeyecek yönde olmasıyla açıklar. Bu durumu Türkiye enflasyon serileri için test ettiğimizde 2003-2018 zaman dilimindeki TÜFE serilerinin ortalaması, 1995-2004 zamana dilimindeki TÜFE serilerine göre daha düşüktür. Aynı şekilde 2002-2018 zaman dilimindeki ÜFE serilerinin direnç değerleri, birkaç seri hariç, 1995-2002 zaman dilimindeki serilerin direnç değerlerinden düşüktür. Dolayısıyla Türkiye enflasyon serilerinin tek değişkenli bir modelde ardışık bağlanım katsayıları toplamıyla tahmin edilerek elde edilen direnç değerlerinin azalmakta olduğu soncu elde edilmiştir. Ancak hem TÜFE hem de ÜFE genel serilerinin sonraki dönemlerdeki düşük direnç değerleri, incelenen bütün dönemdeki enflasyon direncini çok düşük değerlere çekememiş ve Türkiye enflasyon serilerinin direnç değerleri yüksek değerlerdedir.

\section{KAYNAKÇA}

Altınok, S., Şahin, A. ve Çetinkaya, M. (2009). Frekans-Alanda Enflasyon Direnci Araştırması: Türkiye Örneği. Kamu-İs, X, 4.

Altissimo, F., Bilke L., Levin, A, Mathä, T, Mojon, B. (2006). Sectoral and Aggregate Inflation Dynamics in the Euro Area. Journal of the European Economic Association 4(2-3): 585-593.

Bai, J. ve Perron, P. (2003). Computation and Analysis of Multiple Structural Change Models. Journal of Applied Econometrics 18(1): 1-22.

Balcılar, M. (2004). Persistence in Inflation: Does Aggregation Cause Long Memory? Emerging Markets Finance and Trade 40(5): 25-56.

Benati, .2008). Investigating Inflation Persistence Across Monetary Regimes. The Quarterly Journal of Economics 123(3): 1005-1060.

Bilke, L. (2005). Break in the Mean and Persistence of Inflation: A Sectoral Analysis of French CPI. European Central Bank Working Paper No. 463.

Capistran, C. ve Ramos-Francia, M. (2007). “Inflation Dynamics in Latin America”. Meksika Merkez Bankası Çalışma Tebligi, No: $2006-11$.

Cecchetti, S. G. ve Debelle, G. (2006). “Has the Inflation Process Changed?”. Economic Policy 21 (46): 311-352. 
Clark, Todd E. (2006). Disaggregate evidence on the persistence of consumer price inflation. Journal of Applied. Econometrics 21(5): 563587.

Dias, D. ve Marques, C. R. (2005). Using mean reversion as a measure of persistence. European Central Bank Working Paper No. 450.

D’Amato, L., Garegnani, L. ve Sots-Paladina, J. M. (2007). "Inflation Persistence ve Changes in the Monetary Regime: The Argentine Case". Arjantin Merkez Bankası Çalısma Tebliği, No: 23.

Gadzinski, G. ve Orlandi, F. (2004). Inflation Persistence in the European Union, the Euro Area, and the United States. European Central Bank Working Paper No. 414.

Levin, A. T. ve Piger, J. M. (2004). Is Inflation Persistence Intrinsic in Industrial Countries? European Central Bank Working Paper No. 334.

Mishkin, F. S., (2007). Inflation Dynamics, International Finance, 10, 317-334.

Kutlar, A. ve Turgut, T. (2006). Turkiye'de Başlıca Ekonomik Serilerin ARFIMA Modelleri ile Tahmini ve Ongorulebilirliği. Kocaeli Üniversitesi Sosyal Bilimler Enstitüsü Dergisi, 11(1): 120- 149.

Levin, A., Natalucci, F. ve Piger, J. (2004). The Macroeconomic Effects of Inflation Targetting. Federal Reserve Bank St. Louis Review, LXXXVI, $4,51-80$.

Lünneman, P. ve Matha, T. Y. (2004). "How Persistent is Disaggregate Inflation? An Analysis Across EU15 Countries ve HICP Sub-indices". Avrupa Merkez Bankası Çalısma Tebligi, No: 4.

O’Reilly, G., ve Whelan, K.(2005). Has EuroArea Inflation Persistence Changed Over Time? Review of Economics and Statistics, 87(4): 709720.

Özçiçek, Ö. (2011), Türkiye'de Sektörel Enflasyon Direnci, Anadolu Üniversitesi Sosyal Bilimler Dergisi, Cilt: 11, Sayı: 1, 57-68.

Petrassi, M. ve de Oliveira, Fernando N. (2009). Is Inflation Persistence Over? Brezilya Merkez Bankası.

Pivetta, F. ve Reis, R. (2007). The Persistence of Inflation in the United States," Journal of Economic Dynamics and Control, 31(4): 13261358.

Şahin, A. ve Çetinkaya, M.(2009). Zaman Ortamında Sektorel Enflasyon Direnci Hesaplaması: Turkiye Orneği. Finans Politik ve Ekonomik Yorumlar, sayı 537: 23-38.

Taylor, J. (1999). Staggered Price and Wage Setting in Macroeconomics. Handbook of Macroeconomics, vol 1b, Editorler Taylor ve Woodford, North-Holland: 1009-1050.

Yılmazkuday, H. (2009). Inflation Targeting and Inflation Convergence within Turkey. Münih Kisisel Repec Arsiv Çalısması, No: 16770. 